\title{
PREPARAÇÃO PROFISSIONAL EM EDUCAÇÃO FÍSICA: chegamos na idade adulta
}

Roberto Gimenez
Doutorando e mestre em Educação Física. Membro do Laboratório de Comportamento da Escola de Educação Física e Esporte - USP; Professor no Curso de Educação Física - Unicid/Unifieo/ Uninove. robigimen@bol.com.br

\begin{abstract}
Resumo
O presente trabalho discute os conflitos que têm marcado as abordagens norteadoras da formação e a atuação dos profissionais de Educação Física. Para tanto, em primeiro lugar, optou-se por discutir a estrutura dos cursos de graduação até o presente momento, enfocando suas diferentes tendências; em seguida, tratou-se dos desafios que devem ser superados nos próximos anos, em busca da legitimação da profissão.
\end{abstract}

\section{Palavras-chave}

Abordagens da educação física. Educação física. Preparação profissional.

PROFESSIONAL PREPARATION IN PHYSICAL EDUCATION: we reached adult age

\begin{abstract}
The present work aims to accomplish a discussion concerning the conflicts that have been marking the approaches that orientate the formation and the physical education professionals' performance. For so much, first, we opted to discuss the structure of the graduation courses until the present moment, focusing its different tendencies. Finally, it was discussed some challenges that should be overcome in the next years, in search of the legitimation of the profession.
\end{abstract}

\section{Key words}

Physical Education. Physical Education approaches. Professional preparation. 


\section{Introdução}

Marcas no rosto e transformações por todo o corpo decorrentes de mudanças hormonais são características do período da adolescência. Além dessas peculiaridades de ordem fisiológica, é possível destacar outras de ordem comportamental. Adolescentes, geralmente, apresentam conflitos pessoais, desafiam com freqüência a autoridade estabelecida, começam a demonstrar interesse pelo sexo oposto e atribuem especial importância à convivência em grupo. Enfim, a transição que marca o período da adolescência é tão intensa que tem sido denominada de 'crise'. Outros termos atribuídos a essa fase são 'conflito de identidade' ou, no humor do senso comum, 'aborrecência.'

Essas características são típicas de um indivíduo em adaptação que se encaminha para o universo adulto, diferenciado por mais autoridade e responsabilidade, configurando peculiaridades que possibilitam uma analogia do período da adolescência com a fase que a área da Educação Física tem passado, pelo menos, nos últimos vinte e cinco anos. A repercussão do impasse presente nesse campo de atuação profissional, a exemplo do que acontece com o período da adolescência, também contribui para que haja uma série de conflitos, por exemplo, com outras áreas de atuação profissional (GIMENEZ, 1999; 2001), bem como implicam dificuldades em focar um objeto de estudo (MANOEL, 1986; LIMA, 1994), de intervenção (OLIVEIRA, 1991) ou ainda de reconhecimento da Educação Física como uma profissão propriamente dita (LAWSON, 1984; MORFORD, 1972). A crise pode ser considerada tão grande que leva autores a anunciar a possível estagnação da área (BRESSAN, 1979).

Em parte, a discussão sobre os problemas da atuação profissional recai na própria formação profissional em Educação Física, que tem sido alvo de intenso debate, a exemplo de Lima (1994), Lovisolo (1992) e Tani (1996).

O presente ensaio tem por objetivo provocar uma reflexão sobre a graduação na área da Educação Física. 


\section{A evolução da graduação em Educação Física}

Até meados dos anos 70, os cursos de Educação Física no Brasil apresentavam uma formação eminentemente técnica e invariavelmente direcionada à formação de profissionais para o segmento escolar - tratava-se dos cursos clássicos de Licenciatura. A grade curricular apresentava um conjunto de disciplinas sem maior articulação entre si, podendo-se destacar não só aquelas relacionadas ao contexto esportivo, mas também as pedagógicas (voltadas mais especificamente à preparação didático-pedagógica de profissionais para atuar na educação formal), e as disciplinas associadas à área biológica ou da saúde.

A grade curricular marcada somente pela diversidade de disciplinas contribuía para uma formação fragmentada. Em outras palavras, o aluno de graduação recebia ao longo de um período de três ou quatro anos, informações de diferentes naturezas, sem a existência de uma articulação mais efetiva, ou mesmo uma síntese delas (MANOEL, 1999).

Essa visão fragmentada do processo pedagógico contribuiu para a existência de uma dicotomia entre teoria e prática, termo que é utilizado até hoje por alunos e professores de Educação Física. As disciplinas denominadas teóricas eram aquelas orientadas fundamentalmente para a discussão de conceitos didático-pedagógicos, ou para a descrição de processos fisiológicos do organismo humano; por outro lado, as disciplinas chamadas práticas focavam aspectos técnicos e táticos das modalidades esportivas individuais e coletivas.

No que diz respeito à orientação didático-pedagógica, a formação profissional recebeu forte influência da estrutura militar prevalecente. O estilo de ensino predominante nos cursos de graduação para as disciplinas relacionadas ao contexto esportivo era o comando, ou seja, toda a decisão referente à condução do processo pedagógico concentrada nas mãos do professor. Os conteúdos e o processo de avaliação tomavam como forte referência os procedimentos, identificados pela execução correta de atividades motoras propostas pelo docente. Não seria exagero dizer que, grande parte das vezes, o conteúdo das disciplinas ditas 'práticas' estava eminen- 
temente voltado ao aprimoramento da aptidão física dos estudantes de Educação Física. De modo geral, predominava a idéia de que o importante era 'saber fazer' e 'estar apto a'.

Essa organização do projeto pedagógico dos cursos de graduação na área de Educação Física foi alvo de muito debate, sobretudo a partir dos anos 80 . Houve uma série de críticas sobre a fundamentação proporcionada aos professores para atuar no âmbito da escola. Especificamente, as críticas mais contundentes recaíram na falta de conhecimento dos profissionais de Educação Física sobre o ser humano, e até mesmo sobre as relações das propostas da Educação Física com o ideário da escola. A partir desse período, percebeu-se que os cursos de graduação em Educação Física começaram a atribuir uma importância maior às disciplinas teóricas, pois acreditava-se que elas poderiam proporcionar a fundamentação de que os alunos de graduação necessitavam para sua prática profissional. Assim, houve um aumento considerável da carga horária correspondente a essas disciplinas na grade curricular.

Outra reflexão que ganhou vulto foi a de que os estudantes de educação física, uma vez formados em licenciatura, já não apresentavam a escola como foco exclusivo de atuação. Reconhecidamente, os profissionais da área passaram a interagir em contextos diferentes do escolar, o que implicava uma reestruturação de sua formação. Vale citar ainda que esse debate foi acompanhado pelo surgimento de diferentes propostas para a Educação Física. Na ocasião, muitos docentes da área tinham concluído recentemente seus cursos de pósgraduação em programas que surgiram no Brasil e, principalmente, no exterior. Esse fato contribuiu para um redirecionamento de alguns cursos sob a influência de modelos internacionais, ou de propostas teóricas sobre o movimento humano.

Essas mudanças na área culminaram com a criação de alguns cursos de Bacharelado em Educação Física. O primeiro curso foi o da Escola de Educação Física e Esporte da Universidade de São Paulo (USP), que visava formar um profissional habilitado a atuar no segmento não-escolar, com base na idéia de que, mais do que professor, havia a necessidade de formar um profissional que compreendesse efetivamente o ser humano e os aspectos fisiológicos, neurocomportamentais e socioculturais de sua motricidade. Ressalte-se que, para a implantação do modelo da USP, houve uma 
completa reestruturação do projeto pedagógico do curso. O eixo da proposta, norteado por pressupostos desenvolvimentistas, deixou de ser um conjunto de conteúdos disciplinares estanques, passando a estar direcionado para o ser humano em diferentes etapas da vida. Assim, disciplinas clássicas dos cursos de graduação, tais como voleibol, basquetebol ou ginástica rítmica, deixaram de pertencer à grade curricular; seus conteúdos passaram a representar tópicos específicos de outras disciplinas, - Educação Física na Primeira Infância, Educação Física na Segunda Infância, Educação Física na Adolescência, Educação Física na Idade Adulta. Essas reflexões também resultaram na criação de um curso voltado para a formação de profissionais habilitados a trabalhar na gestão esportiva e na preparação técnica e tática no esporte, tendo em vista o alto rendimento - tratava-se do curso de bacharelado em esporte.

Ao mesmo tempo, outros cursos de licenciatura, assumindo a importância da formação específica e técnica relacionada ao gesto esportivo, sobretudo no tocante ao seu impacto no universo cultural, mantiveram as disciplinas técnicas em suas grades curriculares, o que resultou na co-existência de dois cursos com características distintas.

Posteriormente, outras instituições públicas e algumas privadas também criaram seus cursos de bacharelado. Contudo, razoável parte delas não abandonou completamente o curso de licenciatura. Em especial, isso contribuiu para o estabelecimento de cursos conhecidos como 'dois em um', ou seja, oferecia-se um curso tipicamente de bacharelado, mas que preservava muitas características estruturais dos cursos de licenciatura, ou então, o que se pode considerar um problema maior, oferecia-se um curso voltado para a área não-escolar, habilitando profissionais para atuação na Educação Básica.

Embora a gênese dos cursos de Bacharelado em Educação Física fosse fruto de muita discussão e embasamento, ela foi alvo de interpretações deturpadas e até mesmo de uso 'oportunista' por parte de muitos estabelecimentos de ensino. Assim, muitos cursos de formação, por meio de uma estrutura curricular mesclada com disciplinas da Licenciatura e do Bacharelado, asseguraram, durante anos, as duas graduações. 
Quanto à grade curricular, ocorreu efetivamente uma adequação parcial do conteúdo de algumas disciplinas, ou apenas uma mudança nos seus títulos e ementários. A mudança em alguns cursos foi muito mais quantitativa do que qualitativa. Em outras palavras, houve aumento da carga horária de algumas delas, sem reestruturação efetiva de sua proposta em relação a um objetivo mais geral de formação profissional.

\section{O embate no contexto atual}

Concomitantemente ao estabelecimento dos cursos de bacharelado, proliferou uma série de abordagens para a área da Educação Física. Propostas tradicionais foram questionadas, na medida em que se acreditava na necessidade de proporcionar mais embasamento aos profissionais. Assim, um grande número delas surgiu com a finalidade de reformular a atuação vigente.

A abordagem desenvolvimentista, por exemplo (TANI; MANOEL; KOKUBUN; PROENÇA, 1988), surgiu nos anos 80 procurando alertar os profissionais de Educação Física sobre a importância de conhecer e levar em consideração as características e necessidades do ser humano em cada etapa da vida, para o planejamento e implementação de programas de atividade motora. Por se tratar de uma abordagem muito concentrada na discussão da atividade motora, mais especificamente na 'aprendizagem do movimento', foi alvo de muitas críticas, chegando a ser chamada por alguns autores de 'reducionista'. Entretanto, segundo os idealizadores da abordagem desenvolvimentista, o intuito de sua proposta não foi propor um modelo de Educação Física, e sim alertar para a necessidade de fundamentação da prática profissional.

Uma das maiores críticas em relação tanto às abordagens mais tradicionais quanto à desenvolvimentista parte da abordagem "crítico-superadora" (CASTELLANI FILHO, 1988; TAFFAREL; ESCOBAR, 1994; BRACHT, 1995). Em linhas gerais, ela parte do pressuposto de que a Educação Física pode contribuir mais diretamente como um instrumento de transformação social, seja no contexto escolar, seja fora dele. Contudo, essa abordagem também tem sido questionada, pois propõe uma gama de objetivos sociais para a 
Educação Física, sem apresentar modelos mais definidos ou mesmo propostas coerentes de avaliação. Outra crítica se refere ao fato de que, ao almejar objetivos sociais e, muitas vezes, ideológicos, não se contribui para o alcance da especificidade da área, problema que, aliás, também precisa ser sanado.

Outra abordagem foi a humanista-reformista, que segundo Darido (1999), teve como foco central a discussão da dimensão psicológica dos indivíduos. Ela também apresenta críticas formais aos modelos tradicionais, sobretudo no que se refere ao sistema de avaliação empregado com base, quase exclusivamente, em tabelas e curvas-padrão.

Em meados da década de 90, diante do debate entre as abordagens e com grande influência de preceitos da área da Educação, surgiu a abordagem Construtivista (FREIRE, 1989; MATTOS; NEIRA, 1999). Em linhas gerais, seus pressupostos estavam voltados para o uso do movimento como um meio de educar em diferentes esferas, ou seja, à aprendizagem pelo movimento. Dentre as premissas dessa abordagem, destacam-se o trabalho articulado da Educação Física com outras áreas do universo escolar. Entretanto, uma limitação que lhe pode ser imputada é a opercionalização de uma concepção teórica de desenvolvimento em estratégias efetivas de ensino, uma vez que Piaget, seu criador, não avançou na discussão sobre temas a respeito de 'como ensinar'. Enfatize-se que, em muitos parâmetros, essa abordagem se assemelha à desenvolvimentista; contudo, até mesmo por sua finalidade educacional, ela avança na discussão de alguns aspectos pertinentes ao ensino, tais como estilos de ensino, estilos de professor etc. É oportuno ressaltar que esse não foi um objetivo da abordagem desenvolvimentista, uma vez que, embora ela também almejasse atender a necessidades imediatas da preparação profissional, como ampliar o embasamento para o ensino, concentrava-se fundamentalmente na discussão do aluno e de suas características.

Recentemente, tem ganho muita força na área, a abordagem da atividade física e saúde (GUEDES; GUEDES, 1997; NAHAS, 2001). Por se tratar de uma abordagem que se debruça sobre importante problemática da sociedade atual - a falta de atividade motora -, vai ao encontro dos interesses dos serviços de saúde. Não seria exagero afirmar que sua essência estaria muito relacionada às abordagens tradicionais da aptidão física, ou mesmo a um retorno de pressu- 
postos do pensamento higienista (GÓIS JÚNIOR, 2003). Contudo, seus pressupostos centrais desfrutam de mais embasamento sobre aspectos bilógicos do comportamento humano. Além disso, é nítida uma preocupação com a educação do indivíduo, e não meramente com a reprodução de exercícios.

Não há dúvida de que o universo de atuação profissional da Educação Física é difuso e, por isso, necessita de profissionais com visões diferentes. No entanto, a área carece de uma aproximação entre os seus fins. Assim, um aluno de graduação pode perguntar: Qual é a minha função na escola? Recrear? Ensinar gestos típicos de modalidades esportivas? Orientar sobre saúde? Ensinar jogos populares?

Com a intenção de minimizar a fragmentação existente, vários cursos de formação profissional em Educação Física adotaram uma das abordagens para a orientação de suas propostas pedagógicas. Desse modo, o perfil dos profissionais passou a ser mais humanístico ou biológico. Essa concepção, por sua vez, contribui para a formação de profissionais tendenciosos, ou mesmo com uma visão limitada acerca do universo e das possibilidades de intervenção profissional.

Por outro lado, é possível encontrar cursos, a grande maioria, que ficaram no meio do caminho. Constituídos por um corpo docente oriundo de regiões e formações diferenciadas, encontraram severas dificuldades para estabelecer um perfil do profissional formado, o que gerou, em parte, a formação de um profissional que não se aventura a refletir sobre a natureza de sua formação, ou de um indivíduo confuso e com pouca clareza de suas perspectivas profissionais. Isso ocorre quando o aluno de graduação depara com tais discussões no âmbito da universidade, demonstrando freqüentemente confusão ou falta de compreensão das propostas (BORDIN; VIEIRA, 2003).

Em que pesem as vantagens das diferentes perspectivas norteadoras das propostas de formação profissional, as quais poderiam até assegurar um preenchimento mais adequado das vagas do mercado de trabalho, prevalece uma dissonância completa das perspectivas de atuação. Vale ainda citar a existência de um embate acadêmico entre os adeptos das diferentes abordagens, haja vista que nem sempre as discussões são acompanhadas de uma compreensão efetiva de cada uma delas. O resultado disso tem sido um maior 
afastamento entre as propostas e, conseqüentemente, uma maior dificuldade de compreensão por parte dos estudantes de graduação e profissionais mais distantes da realidade acadêmica.

De fato, no bojo dessas dificuldades, acredita-se que alguns caminhos necessitariam ser seguidos pela área, com o intuito de contribuir para a consolidação da profissão.

\section{Tendências e desafios para as próximas décadas}

Tomando como base a expansão dos horizontes de atuação do profissional da área da Educação Física, bem como as crescentes exigências de mais qualificação, é possível destacar a necessidade de profissionais com perfis diferentes, o que não significa formar profissionais por meio de abordagens diferentes.

A idéia central é a de que os cursos de graduação formem um profissional versátil e com recursos para se adaptar aos diferentes contextos de atuação, quer dizer, é importante que ele saia da graduação com uma ampla visão dessas propostas diferentes para a área da Educação Física e que seja capaz de adequá-las a cada contexto de atuação. Para isso, torna-se fundamental que cada curso de graduação, bacharelado ou licenciatura, proporcione discussões sobre as diferentes abordagens, sem, no entanto, apresentar vieses que eventualmente possam distorcer uma compreensão mais efetiva de cada uma delas.

O foco da formação profissional, em vez de primar por fomentar divergências entre as propostas para a área, poderia discutir com mais ênfase seus pontos de convergência, uma vez que nenhuma delas reúne todos os requisitos para a intervenção profissional, impossibilitanto a definição do certo e do errado, o que leva à necessidade de substituir a visão fragmentada por uma complementar da área.

Outro aspecto importante refere-se aos conteúdos, estratégias e avaliação, problemas que os profissionais enfrentam no seu cotidiano. Em outros termos, a área encontra dificuldades para definir o que pode e deve ser feito com as diferentes populações, quais alternativas a utilizar no trabalho e, principalmente, como os resultados e o processo podem ser avaliados. Nesse sentido, merece maior consideração a argumentação em prol do desenvolvimento de pesquisas aplicadas 
e também de caráter integrativo (TANI, 1992). ${ }^{1}$ Essas investigações avançariam em relação ao desenvolvimento de pesquisas básicas, que não satisfazem diretamente aos interesses da intervenção profissional, pois tentariam aplicar os conceitos mais consistentes dessas pesquisas em condições mais próximas das reais condições de ensino.

Em última análise, não cabe uma discussão sobre qual formação seria melhor, se a mais 'humanística' ou a mais 'biológica', uma vez que essa pergunta não tem resposta. Até mesmo as novas diretrizes que guiam a formação profissional não correspondem a uma
1 A Pesquisa Básica está voltada eminentemente para a compreensão dos fenômenos da natureza, sem ter necessariamente uma preocupação com sua aplicabilidade. A Pesquisa Aplicada busca autilizaçãodoconhecimento produzido pela Pesquisa Básica em bens ou recursos utilizáveis pela sociedade (THOMAS; NELSON, 2002). Finalmente, a Pesquisa Integrativa serviria como uma ponte entre a pesquisa básica e aplicada. Esse tipo de pesquisa é fundamental, sobretudo em áreas que têm relação com a transposição do conhecimento e com o ensino.

'camisa de força' para os cursos de graduação. A idéia central é que, independentemente do viés da formação, exista coerência do projeto pedagógico dos cursos com o perfil que propõe formar e, sobretudo, com as possibilidades do mercado de trabalho e as demandas sociais.

Discussões dessa natureza devem incitar reflexões sobre a própria graduação. Dentre elas, é possível destacar questões como: 1) qual a organização mais lógica dos projetos pedagógicos do curso de graduação?; 2) qual a proporção de conteúdos humanísticos, biológicos e socioculturais necessários à formação profissional?; 3) quais disciplinas farão parte dessa formação?; 4) qual a proporção mais adequada entre disciplinas teóricas e práticas?

Essas reflexões contribuiriam para um entendimento mais efetivo das propostas, na tentativa de superar esse período de conflito ou de crise de identidade da área - a adolescência -, assegurando um ingresso mais sólido na idade adulta da profissão. 


\section{Referências}

BORDIN, J.; VIEIRA, S. L. S. Alter: as abordagens da educação física. mimeo. São Paulo: 2003.

BRACHT, V. Mas afinal, o que estamos perguntando com a pergunta "o que é educação física?” Movimento. n. 2, p. 1-8. Rio Grande do Sul: 1995.

BRESSAN, E. S. 2001: The profession is dead: was it murder or suicide? Quest. n. 31, p. 77-82, 1979.

CASTELLANI FILHO, L. Educação Física no Brasil: a história que não se conta. Campinas: Papirus, 1988.

DARIDO, S. A avaliação em Educação Física escolar: das abordagens à prática pedagógica. Anais do V Seminário de Educação Física Escolar. p. 50-68. São Paulo: Cepeusp, 1999.

FREIRE, J. B. Educação de corpo inteiro: teoria e prática da educação física. São Paulo: Scipione, 1989.

GIMENEZ, R. O profissional de educação física na equipe multidisciplinar: caminhos a serem trilhados na busca de identidade. Revista da Sociedade Brasileira de Atividade Motora Adaptada. v. 4, n. 4. São Paulo: 1999.

. Trabalho multidisciplinar com portadores de deficiência mental: o papel do profissional de educação física. Revista de Educação Física da Cidade de São Paulo. n. 1. São Paulo: 2001.

GÓIS JÚNIOR, E. O século da higiene: uma história de intelectuais da saúde. Brasil século XX. Tese de doutorado. Universidade Gama Filho. Rio de Janeiro: 2003. 292 p.

GUEDES, D. P.; GUEDES, E. P. Crescimento, composição corporal e desempenho motor. São Paulo: CLR Baliero, 1997.

LAWSON, H. A. An invitation to physical education. Champaing: Human Kinetics, 1984.

LIMA, J. R. P. Caracterização acadêmica e profissional da Educação Física. Revista Paulista de Educação Física. n. 8, p. 54-67. São Paulo: 1994.

LOVISOLO, H. Educação Física como arte da mediação. Contexto $\mathcal{E}$ Educação. n. 7, p. 39-51. São Paulo: 1992.

MANOEL, E. J. Movimento humano: considerações acerca do objeto de estudo da educação física. Boletim da FIEP. n. 56, p. 33-99. Rio de Janeiro: 1986.

. A dinâmica do estudo e promoção da atividade motora humana: transição de fase na EEFE-USP? Revista Paulista de Educação Física. n. 13, p. 103-118. São Paulo: 1999. 
MATTOS, M. G.; NEIRA, M. G. Educação física escolar: construindo o movimento na escola. São Paulo: Phorte, 1999.

MOFORD, W. R. Toward a profession, not a craft. Quest. n. 8, p. 17-24. New York: 1972.

NAHAS, M. V. Atividade física, saúde e qualidade de vida. Londrina: Midiograf, 2001.

OLIVEIRA, J. G. Mariz de. Educação física escolar: construindo castelos de areia. Revista Paulista de Educação Física. n. 5, p. 5-11. São Paulo: 1991.

TAFFAREL, C. N. Z.; ESCOBAR, M. O. Mas afinal o que é Educação Física?: um exemplo de simplismo intelectual. Movimento. n. 1, p. 35-40. Rio Grande do Sul: 1994.

TANI, G. Estudo do comportamento motor, educação física escolar e a preparação profissional em educação física. Revista Paulista de Educação Física. n. 6, p. 62-66. São Paulo: 1992.

- Cinesiologia, educação física e esporte: ordem emanente do caos na estrutura acadêmica. Motus Corporis. n. 3, p. 9-50. Rio de Janeiro: 1996.

TANI, G.; MANOEL, E. J.; KOKUBUN, E.; PROENÇA, J. E. Educação física escolar: fundamentos para uma abordagem desenvolvimentista. São Paulo: Edusp/EPU, 1988.

THOMAS, J.; NELSON, J. Métodos de pesquisa em atividade física. Porto Alegre: Artmed, 2002. 